\title{
KEMAMPUAN BERBAGAI TINGKATAN STADIUM LARVA KUMBANG Tenebrio molitor L. (COLEOPTERA : TENEBRIONIDAE) DALAM MENGKONSUMSI STYROFOAM (POLYSTYRENE)
}

\author{
THE ABILITY OF VARIOUS LARVAE STAGES OF YELLOW MEALWORM (Tenebrio molitor) \\ (COLEOPTERA: TENEBRIONIDAE) IN CONSUMING STYROFOAM (POL YSTYRENE)
}

\author{
Deasy Vidya Carolina Manullang, Nismah Nukmal, Suratman Umar \\ Jurusan Biologi FMIPA Universitas Lampung \\ JI. Prof. Dr. Soemantri Brodjonegoro No. 1 Bandar Lampung 35145 \\ e-mail: nismah.nukmal@fmipa.unila.ac.id
}

\begin{abstract}
ABSTRAK
Kumbang Tenebrio molitor atau yang lebih dikenal sebagai ulat hongkong, memiliki nilai ekonomis karena dapat digunakan sebagai pakan ternak maupun obat bagi manusia dan mudah dibudidayakan. Ulat hongkong belum dimanfaatkan secara maksimal, sementara ulat hongkong secara alami memiliki manfaat yang besar sebagai pengurai senyawa organik dan anorganik di alam, dari penelitian terakhir diketahui dapat mengurai styrofoam. Penelitian ini dilaksanakan pada Juli-Agustus 2016 di Laboratorium Zoologi Jurusan Biologi Fakultas Matematika dan IImu Pengetahuan Alam Universitas Lampung dengan tujuan untuk mengetahui kemampuan berbagai tingkatan stadium larva ulat hongkong dalam mengkonsumsi styrofoam. Penelitian ini menggunakan Rancangan Acak Lengkap (RAL), dengan 10 instar larva ulat hongkong sebagai perlakuan dan 3 kali pengulangan. Data yang diperoleh dianalisis menggunakan Analisis Ragam (ANARA) dan dilanjutkan uji BNT (Beda Nyata Terkecil) pada taraf beda nyata 5\% serta dilakukan analisis korelasi antara jumlah styrofoam yang dimakan dengan berat serta panjang ulat hongkong. Hasil analisis ragam menunjukkan bahwa pakan styrofoam mempengaruhi berat dan panjang ulat hongkong, serta lama stadium ulat hongkong $(p<0,05)$. Hasil analisis korelasi antara berat ulat hongkong dan jumlah pakan yang dimakan menunjukan adanya hubungan positif yang sangat kuat $(r=0,96)$, dan pada korelasi antara panjang ulat hongkong dan jumlah pakan yang dimakan menunjukkan adanya hubungan postif yang kuat $(r=0,66)$.
\end{abstract}

Kata Kunci : Tenebrio molitor, stadium, styrofoam, konsumsi.

\begin{abstract}
Yellow mealworm (Tenebrio molitor) has economic values such as animal feeding, medicine and easy to rear. Yellow mealworm have not been fully utilized, while yellow mealworm naturally have great benefits as decomposers of organic and inorganic substances and the latest research showed that they can break down styrofoam. This research have been conducted in July-August 2016 at Zoology Laboratory of Biology Department Faculty of Mathematics and Natural Sciences University of Lampung. The aim of the research was to know the ability of various stages of yellow mealworm larvae in consuming styrofoam. This study used Completely Randomized Design (CRD), with 10 stages larvae yellow mealworm as treatments and 3 repetitions. The data were analyzed using Analysis of Variance (ANOVA) and continued by LSD test at level significancy $5 \%$ and analyzed correlation between amount of styrofoam consumed with weight and length of larvae. The results showed that the styrofoam influenced the weight and length of yellow mealworm larvae $(p$ $<0.05)$. The correlation between amount of styrofoam consumed was positive correlation with larvae weight $(r$ $=0,96)$ and lenght $(r=0,66)$
\end{abstract}

Keywords: Tenebrio molitor, stages, styrofoam, consumption 


\section{PENDAHULUAN}

Kumbang Tenebrio molitor atau lebih dikenal sebagai ulat hongkong, memiliki nilai ekonomis karena dapat digunakan sebagai pakan ternak maupun obat bagi manusia dan mudah dibudidayakan (Setiana, 2006). Ulat hongkong secara alami memiliki manfaat yang banyak sebagai pengurai zat-zat organik dan anorganik di alam, dari penelitian terakhir diketahui dapat mengurai styrofoam (Widayat, 2009).

Styrofoam atau polystyrene, banyak digunakan oleh manusia dalam kehidupan sehari-hari dalam bentuk : piring-piring, gelas, kemasan elektronik yang saat ini memenuhi sekitar 25 hingga 30 persen tempat pembuangan sampah (Widayat, 2009).

Menurut Gao, dkk (2010) larva ulat hongkong dapat mengkonsumsi dan mencerna styrofoam. Dari 500 larva ulat hongkong diberi pakan styrofoam seberat 5,8 gram dalam 30 hari, ternyata ulat hongkong yang memakan styrofoam sama sehatnya dengan ulat hongkong yang memakan biji-bijian tetapi informasi mengenai kemampuan setiap tingkatan stadium ulat hongkong dalam mengkonsumsi styrofoam belum diketahui. Oleh karena itu penelitian ini diperlukan untuk mengetahui kemampuan berbagai tingkatan stadium larva ulat hongkong dalam mengkonsumsi styrofoam, dan diharapkan nantinya ulat hongkong dapat dimanfaatkan untuk membantu proses penguraian sampah styrofoam yang dibuang ke lingkungan.

\section{Bahan dan Metode}

Penelitian ini dilakukan di laboratorium Zoologi Fakultas Matematika dan IImu Pengetahuan Alam Universitas Lampung pada Juli - Agustus 2016.
Wadah (insektarium) dibersihkan dan disiapkan sebanyak 24 wadah, yang akan diisi 10 ekor larva dari setiap tingkatan instar yang sudah dipisahkan pada penelitian pendahuluan, masing-masing dengan 3 kali pengulangan (diberi label).

Wadah yang sudah berisi larva diberi pakan styrofoam dengan berat $12 \mathrm{mg}$, dipelihara pada suhu ruang. Objek penelitian diamati setiap 3 hari sekali, hingga terjadi pergantian kulit setiap instar. Kemudian dilakukan penimbangan berat larva, pengukuran panjang larva, dan berat styrofoam yang dimakan. Dengan acuan yang diambil dari penelian Gao, dkk (2010).

Rancangan percobaan yang digunakan dalam penelitian ini adalah Rancangan Acak Lengkap (RAL), dengan 10 instar larva ulat hongkong sebagai perlakuan dan 3 kali pengulangan. Parameter yang diamati adalah berat larva, panjang larva, dan lama waktu pergantian instar. Data yang diperoleh dianalisis menggunakan Analisis Ragam (ANARA) dan dilakukan uji lanjut BNT (Beda Nyata Terkecil) pada taraf 5\% serta dilakukan analisis korelasi antara berat ulat hongkong dan jumlah styrofoam yang dimakan.

\section{Hasil}

A. Pertambahan Berat dan Panjang Ulat Hongkong yang diberi Pakan Styrofoam Hasil analisis ragam memperlihatkan bahwa terdapat pengaruh nyata antara pakan styrofoam yang diberikan terhadap pertambahan berat dan panjang setiap tingkatan ulat hongkong $(p<0,05)($ Tabel 1).

Pada Tabel 1 memperlihatkan bahwa pertambahan berat dan panjang memiliki nilai signifikan. Rata-rata pertambahan berat dan 
85 / Manullang D. V. C., Nukmal N., Umar S.

panjang meningkat sesuai pertambahan tahapan instar. Semakin meningkat tahapan instar maka semakin tinggi pula pertambahan berat dan panjang (Tabel 2), hal ini dikarenakan instar yang lebih tua semakain banyak mengkonsumsi pakan.

Tabel 1. Hasil uji anara pertambahan berat dan panjang ulat hongkong yang diberi pakan styrofoam

\begin{tabular}{llrrrrr}
\hline \multicolumn{2}{c}{ Pakan Styrofoam } & $\begin{array}{c}\text { Jumlah } \\
\text { Kuadrat }\end{array}$ & Df & $\begin{array}{r}\text { Rata-rata } \\
\text { Kuadrat }\end{array}$ & F & Sig. \\
\hline Pertambahan & Antar Kelompok & 0,520 & 7 & 0,074 & 75,929 & 0,000 \\
Berat & Dalam & 0,016 & 16 & 0,001 & & \\
& Kelompok & & & & & \\
& Total & 0,536 & 23 & & & \\
Pertambahan & Antar Kelompok & 0,285 & 7 & 0,041 & 14,873 & 0,000 \\
Panjang & Dalam & 0,044 & 16 & 0,003 & & \\
& Kelompok & & & & & \\
& Total & 0,329 & 23 & & & \\
\hline
\end{tabular}

Keterangan : Angka yang diikuti oleh huruf yang tidak sama berbeda nyata pada uji BNT dengan taraf signifikan $5 \%$

Tabel 2. Rata-rata pertambahan berat dan panjang setiap instar larva ulat hongkong yang diberi pakan styrofoam

\begin{tabular}{ccc}
\hline $\begin{array}{c}\text { Instar } \\
\text { ke }\end{array}$ & $\begin{array}{c}\text { Pertambahan Berat } \\
(\mathbf{m g} \pm \mathbf{s d})\end{array}$ & $\begin{array}{c}\text { Pertambahan } \\
\text { Panjang } \\
(\mathbf{m m} \pm \mathbf{~ s d})\end{array}$ \\
\hline $1-2$ & $0,41 \pm 0,04^{\mathrm{a}}$ & $0,83 \pm 0,10^{\mathrm{a}}$ \\
$2-3$ & $0,46 \pm 0,01^{\mathrm{a}}$ & $0,86 \pm 0,05^{\mathrm{a}}$ \\
$3-4$ & $0,53 \pm 0,00^{\mathrm{b}}$ & $0,86 \pm 0,07^{\mathrm{a}}$ \\
$4-5$ & $0,59 \pm 0,01^{\mathrm{c}}$ & $0,89 \pm 0,03^{\mathrm{a}}$ \\
$5-6$ & $0,66 \pm 0,03^{\text {def }}$ & $0,90 \pm 0,00^{\mathrm{a}}$ \\
$6-7$ & $0,71 \pm 0,02^{\text {ef }}$ & $0,90 \pm 0,00^{\mathrm{a}}$ \\
$7-8$ & $0,76 \pm 0,06^{\mathrm{f}}$ & $1,02 \pm 0,03^{\mathrm{b}}$ \\
$8-9$ & $0,88 \pm 0,01^{\mathrm{g}}$ & $1,18 \pm 0,02^{\mathrm{c}}$ \\
\hline
\end{tabular}

Instar 1-2, 2-3, 5-6, dan 6-7 menunjukkan tidak adanya perbedaan nyata pertambahan berat yang terjadi pada instar tersebut tidak mengalami peningkatan bobot yang signifikan pada ulat hongkong. Hal ini dikarenakan instar 1-2 dan 2-3 merupakan instar awal yang baru memasuki tahap perkembangan, sedangkan pada instar 5-6 dan 67 merupakan instar yang sudah berkembang dan akan memasuki fase pupa.

Pada pertambahan panjang menunjukkan ada perbedaan nyata pada instar 7-8 dan 8-9, hal ini dikarenakan pertambahan panjang yang terjadi pada instar tersebut mengalami peningkatan ukuran yang signifikan, hal ini mungkin disebabkan karena meningkatnya kemampuan makan untuk persiapan memasuki fase pupa.

\section{B. Pakan Ulat Hongkong}

Rata-rata kemampuan setiap instar ulat hongkong dalam mengkonsumsi styrofoam berbeda nyata (Gambar 1).

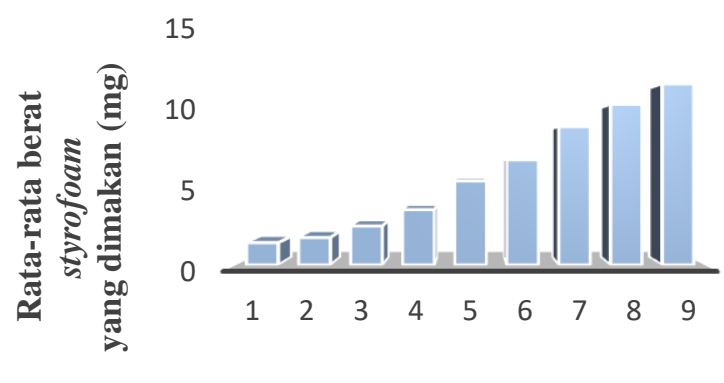

Instar

Gambar 1. Kemampuan setiap instar ulat hongkong dalam mengkonsumsi styrofoam

Kemampuan memakan styrofoam pada ulat hongkong meningkat sejalan dengan peningkatan instar (Gambar 1). Kemampuan makan instar 8 lebih banyak 6,6 kali dibadingkan instar 1, kemampuan makan instar 5 lebih banyak 3,8 kali dibandingkan instar 1, dan kemampuan makan instar 8 lebih banyak 1,7 kali dibandingkan instar 5 .

Laju konsumsi pakan dan laju pertumbuhan ulat hongkong hampir sama yaitu mengikuti pola pertumbuhan polynomial (Gambar 2), terjadi 
peningkatan laju konsumsi pakan pada setiap instar akan tetapi pada instar 5-6 terjadi penurunan laju konsumsi, hal ini diduga karena perubahan fisiologi larva dalam memasuki persiapan fase pupa dan pada instar 7-8 terjadi penurunan kembali yang disebabkan instar yang akan memasuki fase pupa atau stadium istirahat.

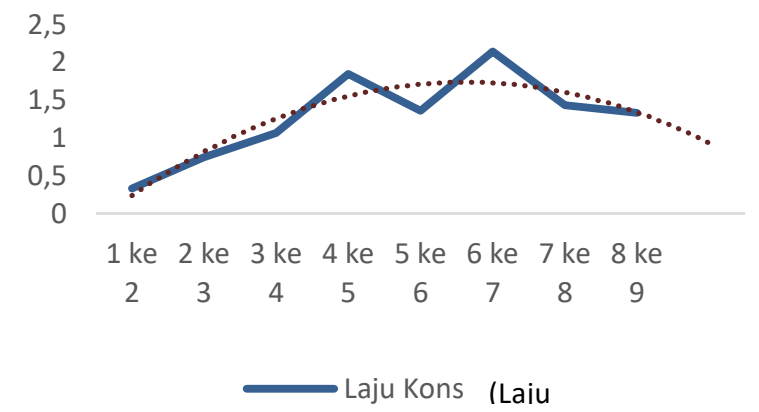

Gambar 2. Laju pertumbuhan dan konsumsi pakan styrofoam setiap instar ulat hongkong

\section{Lama Stadium}

Hasil analisis ragam memperlihatkan bahwa terdapat pengaruh nyata antara pakan styrofoam yang diberikan terhadap lama stadium ulat hongkong $(p<0,05)$ (Tabel 3).

Tabel 3. Hasil uji anara lama stadium ulat hongkong yang diberi pakan styrofoam

\begin{tabular}{lrrrrr}
\hline $\begin{array}{c}\text { Lama Stadium } \\
\text { dengan pakan } \\
\text { styrofoam }\end{array}$ & \multicolumn{1}{c}{$\begin{array}{c}\text { Jumlah } \\
\text { Kuadrat }\end{array}$} & Df & $\begin{array}{c}\text { Rata-rata } \\
\text { Kuadrat }\end{array}$ & F & Sig. \\
\hline Antar Kelompok & 0,183 & 8 & 0,023 & 6,175 & 0,001 \\
Dalam Kelompok & 0,067 & 18 & 0,004 & & \\
Total & 0,250 & 26 & & & \\
\hline
\end{tabular}

Rata-rata lama stadium yang dibutuhkan larva ulat hongkong untuk berubah dari instar rendah ke instar yang lebih tinggi berkisar antara 3,00-3,56 hari, dengan frekuensi moulting sebanyak 10 kali sebelum menjadi pupa dalam 3 - 4 minggu. Lama stadium instar 1 berbeda nyata dengan lama stadium instar 9, hal ini dikarenakan instar 1 merupakan instar awal yang baru memasuki tahap perkembangan sehingga lama stadiumnya lebih cepat dibandingkan instar 9 yang akan memasuki fase pupa (Tabel 4).

Tabel 4. Rata-rata \pm sd lama stadium setiap instar ulat hongkong yang diberi pakan Styrofoam

\begin{tabular}{cc}
\hline Instar & Lama Stadium (hari) \\
\hline 1 & $3,26 \pm 0,05 \mathrm{a}$ \\
2 & $3,13 \pm 0,05 \mathrm{abc}$ \\
3 & $3,06 \pm 0,11 \mathrm{bc}$ \\
4 & $3,20 \pm 0,00 \mathrm{ab}$ \\
5 & $3,10 \pm 0,00 \mathrm{bc}$ \\
6 & $3,00 \pm 0,00 \mathrm{c}$ \\
7 & $3,06 \pm 0,05 \mathrm{bc}$ \\
8 & $3,10 \pm 0,10 \mathrm{bc}$ \\
9 & $3,56 \pm 0,05 \mathrm{~d}$ \\
\hline
\end{tabular}

Keterangan : Angka yang diikuti oleh huruf yang tidak sama berbeda nyata pada uji BNT dengan taraf signifikan 5\%

\section{Pembahasan}

Rata-rata pertambahan berat dan pertambahan panjang larva ulat hongkong semakin betambah sejalan dengan peningkatan tahapan instar dan peningkatan jumlah pakan yang dikonsumsi. Hal ini sesuai dengan hasil penelitian Sihombing (1999), bahwa setiap larva yang bertambah tahapan instarnya akan mengalami moulting dan pertambahan berat serta panjang.

Kemampuan memakan styrofoam pada ulat hongkong akan semakin meningkat dengan bertambahnya tingkatan instar, oleh sebab itu instar akhir lebih banyak mengkonsumsi styrofoam dibandingkan instar awal. Hal ini disebabkan instar akhir yang mau memasuki fase pupa lebih banyak membutuhkan pakan dibandingkan instar awal yang dalam masa pertumbuhan. Hal ini sesuai dengan penelitian Sitompul (2006) bahwa instar akhir lebih banyak mengkonsumsi pakan 
87 / Manullang D. V. C., Nukmal N., Umar S.

dibandingkan instar awal, karena larva instar akhir sudah mulai memasuki masa pupa. Menurut Ross et al. (1982) pada instar awal, serangga mengkonsentrasikan energinya untuk pertumbuhan dan pada instar akhir, serangga mengkonsentrasikan energinya untuk measuki fase pupa.

Laju konsumsi pakan pada ulat hongkong terjadi peningkatan pada setiap instar kecuali pada instar 5-6 terjadi penurunan. Hal ini mungkin disebabkan pengaruh fisiologis pada ulat hongkong dalam persiapan memasuki fase pupa.

Menurut Noerdjito (2003), instar larva akhir atau memasuki fase pupa akan lebih sedikit beraktivitas dan terjadi penurunan konsumsi, hal ini dikenal sebagai stadium istirahat.

Lama stadium ulat hongkong instar awal berbeda nyata dengan instar akhir, hal ini dikarenakan instar awal merupakan instar dalam tahap perkembangan sehingga lama stadiumnya lebih cepat dibandingkan instar akhir. Menurut Dish (2006), instar awal ulat hongkong memiliki lama waktu perkembangan instar $3-4$ hari, sedangkan instar akhir yang memasuki fase pupa memiliki lama waktu perkembangan instar $3-6$ hari.

Pada instar akhir memiliki lama stadium yang lebih lama dibandingkan instar lainnya, hal ini dikarenakan instar akhir merupakan instar terakhir yang akan memasuki tahap lanjutan untuk menjadi pupa. Instar yang memasuki fase pupa tidak banyak makan, tidak terlalu aktif karena memasuki stadium istirahat dan mengalami lama stadium lebih lama (Noerdjito, 2003).

Hasil analisis korelasi antara jumlah pakan dan berat larva ulat hongkong (Gambar 3) menunjukkan bahwa ada korelasi positif yang sangat kuat. Menurut Sugiyono (2007), koefisien korelasi antara 0,80-1,00 merupakan korelasi yang sangat kuat.

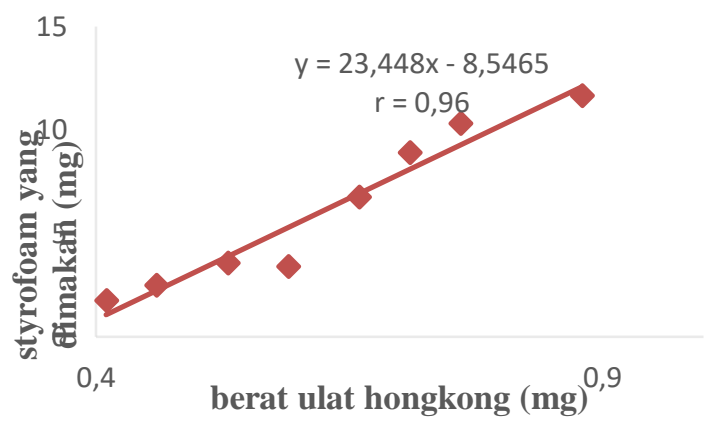

Gambar 3. Korelasi antara berat styrofoam yamg dimakan dan pertambahan berat ulat hongkong

Hasil analisis korelasi antara pakan dan ukuran panjang larva ulat hongkong menunjukkan adanya korelasi yang kuat (Gambar 4). Menurut Sugiyono (2007), koefisien korelasi antara 0,60-0,79 merupakan korelasi yang kuat.

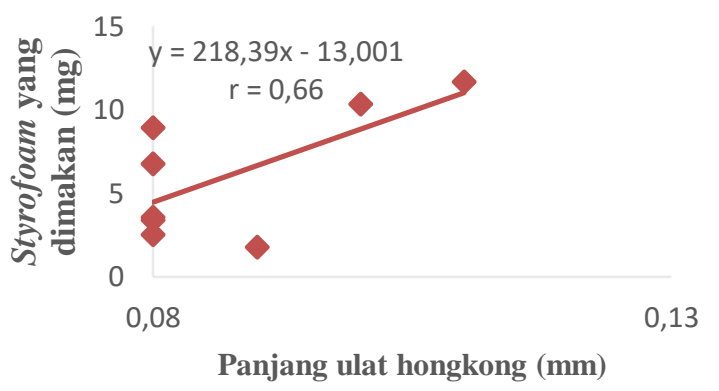

Gambar 4. Korelasi antara pakan styrofoam dan pertambahan panjang ulat hongkong

Hubungan korelasi di atas dapat dilihat styrofoam lebih berpengaruh terhadap berat dibandingkan panjang, hal ini dikarenakan pertambahan berat ulat hongkong akan terus meningkat seiring bertambahnya tahapan instar sama halnya dengan panjang ulat hongkong, pertambahan panjang terus terjadi dan mengalami peningkatkan tetapi ketika ulat hongkong akan memasuki fase pupa biasanya diikuti dengan pemendekan atau pengkerutan panjang badan. Hal ini sesuai dengan 
pernyataan Sitompul (2006) bahwa kondisi ini menunjukkan pertumbuhan ulat hongkong pada fase awal adalah pertambahan panjang badan sedangkan pada fase akhir adalah pertambahan bobot badan.

\section{KESIMPULAN}

Dari hasil penelitian yang telah dilakukan dapat disimpulkan bahwa kemampuan berbagai tingkatan stadium ulat hongkong dalam mengkonsumsi styrofoam berbeda-beda, semakin tua tingkat instar ulat hongkong maka semakin banyak styrofoam yang dikomsumsi.

\section{DAFTAR PUSTAKA}

Dish, C. 2006. Superworms, Mealworms, and Giant Mealworms. diakses : www.chameleonsdish.com/insects/wormdi ff.htm. diunduh : 11 Juli 2008.

Gao, D., Yuan, X., Liang, H., and Wu, W.M. 2010. "Comparison of biological removal via nitrite with real-time control using aerobic granular sludge and flocculent activated sludge", Appl MicrobiolBiotechnol, 89 (10) : 1645-1652.

Noerdjito, W. A., 2003, Keragaman kumbang (Coleoptera). di dalam: Amir M, Kahono S. Serangga taman nasional Gunung Halimun Jawa Bagian Barat, JICA Biodiversity Conservation Project, 149200.

Ross, H.H., C.A. Ross and J.R.P.Ross. 1982. A Textbook of Entomology. 4 Edit. John Willey and Sons Inc. New York.

Setiana, D. 2006. Jumlah dan bobot massa larva ulat Tenebrio molitor pada media bertelur yang berbeda. (Skripsi). Fakultas Peternakan. Institut Pertanian Bogor. Bogor.

Sihombing, D. T. H. 1999. Satwa Harapan I: Cacing Tanah, Bekicot, Keong, Kupu-kupu, Ulat Hongkong. Pengantar Ilmu dan Teknologi Budidaya. Pusaka Wirausaha Muda. Bogor.
Sitompul, R. H. 2006. Pertumbuhan dan konversi pakan ulat tepung (Tenebrio molitor L.) pada kombinasi pakan komersial dengan dedak padi, onggok, dan pollard. (Skripsi). Fakultas Peternakan. Institut Pertanian Bogor. Bogor.

Sugiyono. 2007. Metode penelitian pendidikan pendekatan kuantitatif, kualitatif, dan $R \& D$. Alfabeta. Bandung.

Widayat, W. 2009. Pemanfaatan mealworm (Larva Tenebrio molitorL.) sebagai solusi pencemaran tanah dari sampah plastik. (Skripsi). Jurusan Hama dan Penyakit Tumbuhan Institut Pertanian Bogor. Bogor. 